\title{
EXPOSURE TO ELEVATED TEMPERATURES AND COOLED UNDER DIFFERENT REGIMES - A STUDY ON BLENDED CONCRETE
}

\author{
Subhash C. Yaragal ${ }^{1}$, Darshan Patel ${ }^{2}$, K S Babu Narayan ${ }^{3}$ \\ ${ }^{1}$ Professor, Dept. of Civil Engineering, National Institute of Technology, Karnataka, India, subhashyaragal@yahoo.com \\ ${ }^{2}$ Post Graduate Student, Dept. of Civil Engineering, National Institute of Technology, Karnataka, India \\ ${ }^{3}$ Professor, Dept. of Civil Engineering, National Institute of Technology, Karnataka, India
}

\begin{abstract}
Fire is one of the most destructive powers to which a building structure can be subjected, often exposing concrete elements to elevated temperatures. The relative properties of concrete after such an exposure are of great importance in terms of the serviceability of buildings. Unravelling the heating history of concrete and different cooling regimes is important to forensic research or to determine whether a fire-exposed concrete structure and its components are still structurally sound or not. Assessment of fire-damaged concrete structures usually starts with visual observation of colour change, cracking and spalling. Thus, it is important to know the effect of elevated temperatures on strength retention properties of concrete. This study reports the effect of elevated temperature on the mechanical properties of the concrete specimen obtained by replacing 30\% OPC by GGBS and cooled differently under various regimes. In the heating cycle, the specimen were subjected to elevated temperatures ranging from $150{ }^{\circ} \mathrm{C}$ to $550{ }^{\circ} \mathrm{C}$, in steps of $100{ }^{\circ} \mathrm{C}$ with a retention period of 1 hour. Then the cooling regimes studied include, furnace cooling, air cooling and sudden cooling. After exposure to elevated temperatures and cooled differently, the weight loss, residual compressive and split tensile strengths retention characteristics are studied. Test results indicated that weight and both strengths significantly reduce with an increase in temperature and are strongly dependent on cooling regimes adopted.
\end{abstract}

Index Terms: Elevated temperature, Residual compressive strength, Cooling regimes, and Blended concretes

\section{INTRODUCTION}

Concrete is the most-used man-made material on earth. However its main constituent, clinker-based cement has relatively high carbon footprint and high release of energy. The use of cement with lower environmental burdens offers opportunities for significant reduction in energy and lower rate of carbon emission. The most effective alternative to Portland cement is Ground Granulated Blast Furnace Slag, which can reduce up to $40 \%$ of $\mathrm{CO}_{2}$ emission.

Concrete is subjected to high temperature during fire accidents, natural disasters, and sabotages. Even though concrete is the best available material for construction, it has some constraints like reduction in strength, loss of weight, shrinkage, expansion, deterioration etc. When concrete is exposed to $600^{\circ} \mathrm{C}$ has shown better strength and durability recovery than that exposed to $800^{\circ} \mathrm{C}$ (Xu Y. et al., 2003). The reason was that the decomposition of structure of the $\mathrm{C}-\mathrm{S} \mathrm{H}$ gel starts at about $550^{\circ} \mathrm{C}$.

Poon C. S. et al. (2001), have observed that all slag cement paste specimen experienced an increase in strength between $100^{\circ} \mathrm{C}$ and $250^{\circ} \mathrm{C}$. Tests were performed on cement paste containing $0 \%, 50 \%, 70 \%, 90 \%$ replacement of slag by weight with OPC. Of all, 70\% replacement slag showed best results as regards to residual compressive strength.
Bingol and Gul (2008), observed that until 4000C air cooled concrete maintained $80 \%$ of its original strength. After $400^{\circ} \mathrm{C}$ both types of $\mathrm{C} 20$ and $\mathrm{C} 35$ lost their strength rapidly and strength loss was more in case of water cooled specimen. The mechanical strength of $\mathrm{C} 20$ decreased in a similar manner to that of C35 when subjected to high temperatures. Moreover, air-cooled specimens maintained a greater proportion of their relative residual compressive strength than the water-cooled specimen. The highest losses in strength for both concrete types are recorded in the specimen that are heated to $700^{\circ} \mathrm{C}$ and then cooled in water.

In this experimental investigation the deterioration in strengths of blended concrete when subjected to elevated temperatures and when cooled gradually, moderately or suddenly in reported.

\section{MATERIALS AND METHODS}

$100 \mathrm{~mm}$ concrete cubes were cast based on the results of trial mix design for M20 grade of concrete. The proportion is C: GGBS: FA: $20 \mathrm{~mm}: 10 \mathrm{~mm}$ is $0.7: 0.3: 1.116: 2.045: 0.876$ at $\mathrm{w} / \mathrm{c}$ of 0.45 . The measured slump is $95 \mathrm{~mm}$. 


\subsection{Electric Furnace Temperature Build-Up}

The specimen was placed in the furnace, target temperatures are adjusted using the knob and temperature increase is noted at appropriate intervals of time, till it reaches the target temperature. Figure 1 shows the furnace time temperature build up curve.

From Figure 1, it is observed that the temperature build up till $4000 \mathrm{C}$ is at a faster rate of $200 \mathrm{C} / \mathrm{min}$ compared to temperature built up above 4000C. Temperature build-up is gradual above $4000 \mathrm{C}$ and is at the rate of $70 \mathrm{C} /$ minute.

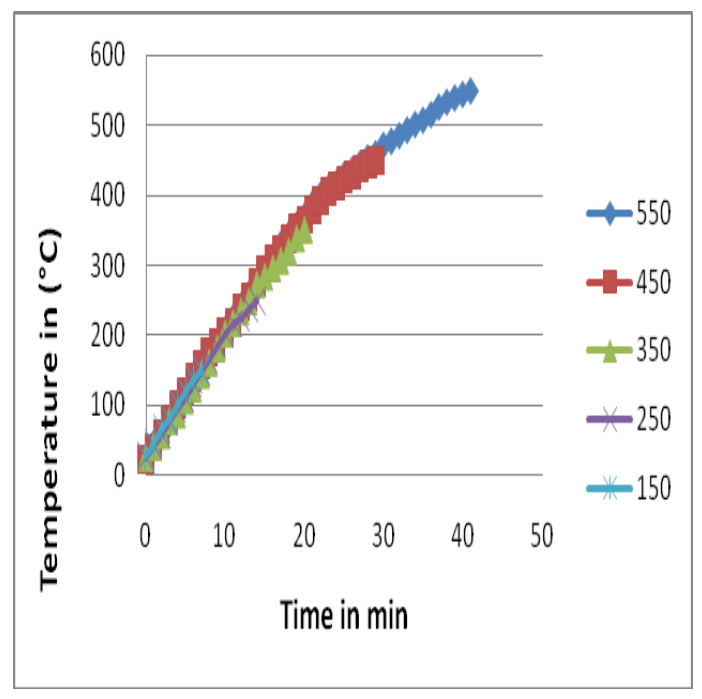

Fig.1 Time temperature build-up curve for the furnace

\subsection{Specimen cooling}

In the furnace cooling, after exposing the cubes to the designated temperature they were allowed to cool in the furnace itself till the room temperature was reached.

For air cooling, after exposing the cubes to the required temperature, they were removed from the furnace and were placed outside on floor in air which was allowed to cool till room temperature.

For sudden cooling in water, after exposing the cubes to the required temperature, they were removed from the furnace and immediately were placed in the tub of water which was allowed to cool till room temperature.

Afterwards the weight loss of specimen was noted and the destructive tests were performed for residual compressive and split tensile strength evaluation.

\section{RESULTS AND DISCUSSION}

Important results relating to loss in weight and loss in strength for three cooling regimes is presented and discussed

\subsection{Loss in Weight of Specimen}

Initial specimen weights were taken after 28 days of water curing. After exposure to various elevated temperatures and cooled under different cooling regimes (furnace, air and sudden) the weights of the specimen were recorded to determine the percentage loss in weight.

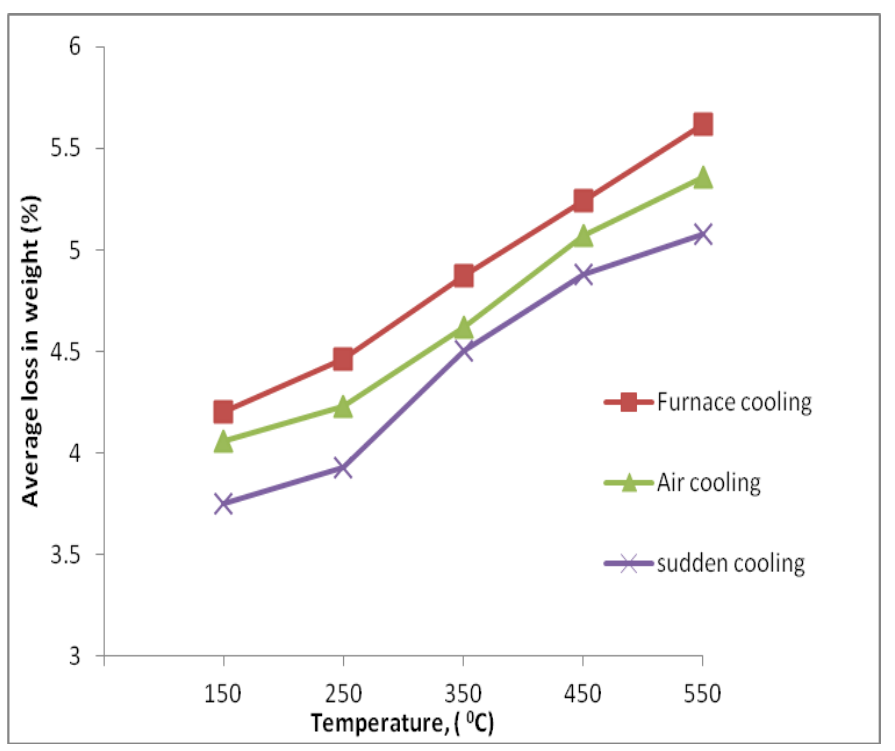

Fig.2 Variation in percentage loss in weight for exposure and cooling under different regimes

From Figure 2, it is observed that for the case of furnace cooling, $74.7 \%$ of total weight loss occurs when exposed to $1500 \mathrm{C}$. The remaining $25.3 \%$ weight is lost, which is gradually with increments of $4.6 \%$ for temperature change of $1500 \mathrm{C}$ to $2500 \mathrm{C}, 7.3 \%$ for temperature change of $2500 \mathrm{C}$ to $3500 \mathrm{C}, 6.6 \%$ for temperature change of $3500 \mathrm{C}$ to $4500 \mathrm{C}$ and $6.8 \%$ for temperature change of $4500 \mathrm{C}$ to $5500 \mathrm{C}$.

From Figure 2, it is observed that for the case of air cooling, $75.7 \%$ of total weight loss occurs when exposed to $1500 \mathrm{C}$. The remaining $24.3 \%$ weight is lost, gradually with increments of $3.2 \%$ for temperature change of $1500 \mathrm{C}$ to $2500 \mathrm{C}, 8.6 \%$ for temperature change of $2500 \mathrm{C}$ to $3500 \mathrm{C}$, $7.3 \%$ for temperature change of $3500 \mathrm{C}$ to $4500 \mathrm{C}$ and $8.4 \%$ for temperature change of $4500 \mathrm{C}$ to $5500 \mathrm{C}$.

From Figure 2, it is observed that for the case of sudden cooling, $73.8 \%$ of total weight loss occurs when exposed to $1500 \mathrm{C}$. The remaining $26.2 \%$ weight is lost, gradually with increments of $3.5 \%$ for temperature change of $1500 \mathrm{C}$ to $2500 \mathrm{C}, 11.2 \%$ for temperature change of $2500 \mathrm{C}$ to $3500 \mathrm{C}$, $7.5 \%$ for temperature change of $3500 \mathrm{C}$ to $4500 \mathrm{C}$ and $4 \%$ for temperature change of $4500 \mathrm{C}$ to $5500 \mathrm{C}$. 


\subsection{Variation in Residual Compressive Strength for}

\section{Different Cooling Regimes}

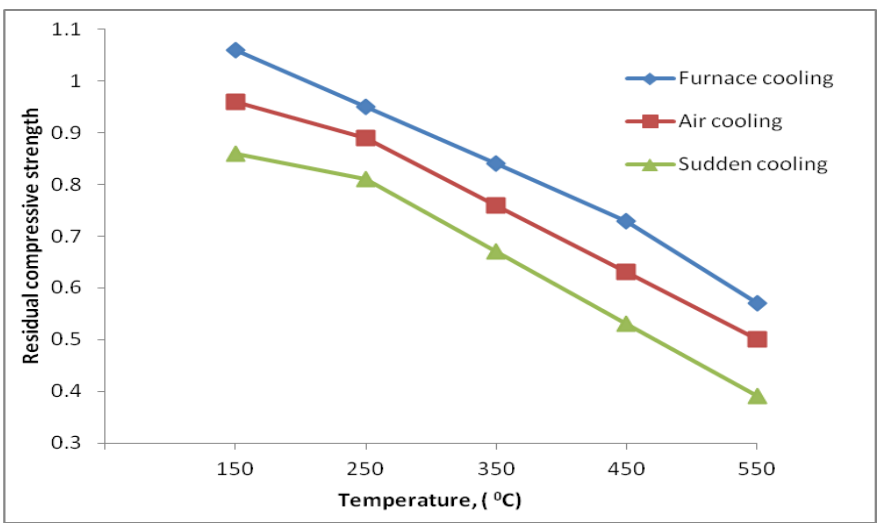

Fig.3 Variation in residual compressive strength for exposure and cooling under different regimes

From Figure 3, it is observed that for furnace cooling the residual coefficient of compressive strength of cubes exposed to $1500 \mathrm{C}$ is slightly higher by about $6 \%$ than that of cubes tested at normal room temperature. This is mainly because, at earlier elevated temperatures the moisture content in the cubes gets converted to vapour pressure, which contributed to the additional compressive strength than that of normal strength at room temperature as also observed by Saava A. et al. (2005), Husem M. (2005), Xu Y. et al. (2003). This effect is called as autoclaving effect.

On further increase of temperature there is loss in compressive strength gradually, as compared to strength at room temperature due to loss of moisture content and disintegration of hydrated cement paste. At $2500 \mathrm{C}$ the residual coefficient of compressive strength is 0.95 , and drops gradually to $0.84,0.73$ and 0.57 at elevated temperatures of $3500 \mathrm{C}, 4500 \mathrm{C}$ and $5500 \mathrm{C}$ respectively for the furnace cooling which is gradual.

For the case of air cooling, it is observed that the residual coefficient of compressive strength of cubes exposed to $1500 \mathrm{C}$ is 0.96 and drops gradually to $0.89,0.76,0.63$ and 0.50 at elevated temperatures of $1500 \mathrm{C}, 2500 \mathrm{C}, 3500 \mathrm{C}, 4500 \mathrm{C}$ and 5500C.

Further, for the case of sudden cooling, it is observed that the residual coefficient of compressive strength of cubes exposed to $1500 \mathrm{C}$ is 0.86 and drops gradually to $0.81,0.67,0.53$ and 0.39 at elevated temperatures of $1500 \mathrm{C}, 2500 \mathrm{C}, 3500 \mathrm{C}$, 4500C and 5500C.

The percentage difference in furnace cooling and air cooling regimes are $10,6,8,10$ and 7 respectively for $1500 \mathrm{C}, 2500 \mathrm{C}$, $3500 \mathrm{C}, 4500 \mathrm{C}$ and $5500 \mathrm{C}$. On an average $8 \%$ change is reported for temperature of $3500 \mathrm{C}$ and above.
The percentage difference in furnace cooling and sudden cooling regimes are $20,14,17,20$ and 18 respectively for $1500 \mathrm{C}, 2500 \mathrm{C}, 3500 \mathrm{C}, 4500 \mathrm{C}$ and 5500C. On an average $17 \%$ change is reported for temperature of $3500 \mathrm{C}$ and above.

\subsection{Variation in Residual Split Tensile Strength for Different Cooling Regimes}

From figure 4 , it is observed that the residual split tensile strength of cubes exposed to $1500 \mathrm{C}$ is 0.92 and drops gradually to $0.86,0.76,0.63$ and 0.56 at elevated temperatures of $2500 \mathrm{C}, 3500 \mathrm{C}, 4500 \mathrm{C}$ and $5500 \mathrm{C}$ for the case of furnace cooling which is gradual.

For the case of air cooling, it is observed that the residual coefficient of split tensile strength of cubes exposed to $1500 \mathrm{C}$ is 0.77 and drops gradually to $0.73,0.63,0.46$ and 0.39 at elevated temperatures of $2500 \mathrm{C}, 3500 \mathrm{C}, 4500 \mathrm{C}$ and $5500 \mathrm{C}$.

Further, for the case of sudden cooling, it is observed that the residual coefficient of split tensile strength of cubes exposed to $1500 \mathrm{C}$ is 0.58 and drops gradually to $0.53,0.45,0.37$ and 0.30 at elevated temperatures of $2500 \mathrm{C}, 3500 \mathrm{C}, 4500 \mathrm{C}$ and 5500C.

The percentage difference furnace cooling and air cooling regimes are $15,13,13,17$ and 17 respectively for $1500 \mathrm{C}$, 2500C, 3500C, 4500C and 5500C. There is a decreasing variation from $13 \%$ to nearly $17 \%$ for temperature change of $1500 \mathrm{C}$ to $5500 \mathrm{C}$.

The percentage difference furnace cooling and sudden cooling regimes are $34,33,31,26$ and 26 respectively for $1500 \mathrm{C}$, $2500 \mathrm{C}, 3500 \mathrm{C}, 4500 \mathrm{C}$ and $5500 \mathrm{C}$. There is a decreasing variation from $34 \%$ to nearly $26 \%$ for temperature change of $1500 \mathrm{C}$ to $5500 \mathrm{C}$.

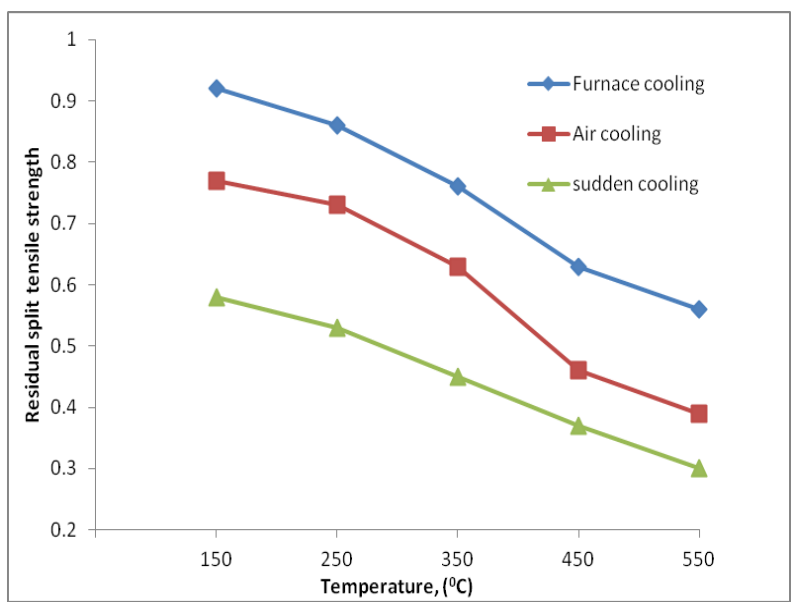

Fig.4 Variation in residual split tensile strength for exposure and cooling under different regimes 


\section{CONCLUSIONS}

The following conclusions are deduced from this study:

- The total percentage weight loss of the specimen increases as the exposure temperature increases, for all the three cases of cooling regimes, however this is maximum for furnace cooled and minimum for sudden cooling. The case of air cooling lies midway between the two.

- The residual coefficient of compressive strength decreases with increase in temperature except at early elevated temperature around $150^{\circ} \mathrm{C}$ due to autoclaving effect under furnace cooling.

- Rate of loss in strength of concrete is highly dependent on the type of cooling regimes. The loss of compressive and split tensile strength is minimum under furnace cooling and air cooling as the heat gradient is gradual and in order and maximum under sudden cooling, as the thermal shock is sudden.

\section{REFERENCES:}

[1]. Bingol, A F and Gul, R (2008), Effect of elevated temperatures and cooling regimes on normal strength concrete, Fire and Materials, Vol.33, pp. 79-88.

[2] Poon, C S et al.(2001), Comparison of the strength and durability performance of normal- and high-strength pozzolanic concretes at elevated temperatures, Cement and Concrete Research, Vol. 31, pp.1291-1300

[3] Savva, A et al. (2005), Influence of elevated temperatures on the mechanical properties of blended cement concretes prepared with limestone and siliceous aggregates, Cement and Concrete Composites, Vol. 27, pp. 239-248.

[4] Xu, Y et al. (2003), Influence of PFA on cracking of concrete and cement paste after exposure to high temperatures, Cement and Concrete Research, Vol. 33, pp.2009-2016.

[5] Luo, X et al. (2000), Effect of heating and cooling regimes on residual strength and microstructure of normal strength and high-performance concrete, Cement and Concrete Research, Vol. 30, pp. 379-383.

[6] Husem, M. (2006), The effects of high temperature on compressive \& flexural strengths of ordinary and highperformance concrete, Fire Safety Journal, Vol. 41, pp.155163.

\section{BIOGRAPHIES:}



Subhash C Yaragal graduated from NITK Surathkal and obtained his post graduation and doctoral degrees from the Indian Institute of Science, Bangalore. Currently he is serving as Professor and Associate Dean (Academic). His areas of interest include concrete technology, concrete performance and building aerodynamics and wind tunnel testing.

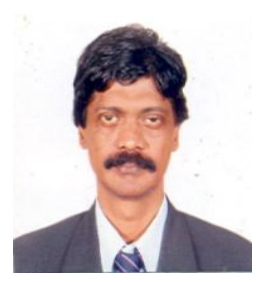

Babu Narayan obtained his B.Tech (Civil) from NITK Surathkal and Master's degree from IIT Mumbai. He obtained his doctoral degree from NITK Surathkal. Currently he is serving as Professor. His areas of interest include tall structures and structural optimization. 